\title{
Chronic anaemia causes degenerative changes in trophoblast cells of the rat placenta
}

\author{
Omer Awad, Shem J. Ochieng, Abdel Malek, Julius Ogeng'o \\ Department of Human Anatomy, University of Nairobi, Nairobi, Kenya
}

\begin{abstract}
Objectives: Iron deficiency anaemia causes adverse pregnancy outcome. There are few studies on effects of anaemia on the structure of trophoblastic cells which are important in placental function. These data are important for understanding the function and disorders of the placenta. The aim of this study was to investigate the ultrastructural cellular changes associated with iron deficiency anaemia in rat placenta.

Methods: Forty-nine female Sprague-Dawley rats were randomly separated into experimental and control groups. The experimental group was rendered anaemic by removing $1.5 \mathrm{ml}$ of blood per bleed on five alternate days, and the placentas were collected on gestational days 17, 19 and 21. For light microscopy, five cubic millimeter segments were fixed in $10 \%$ buffered formaldehyde solution; dehydrated in ethanol and embedded in paraffin wax. Five micron thick sections were cut, deparaffinized and stained with Hematoxylin and Eosin. For transmission electron microscopy, $1 \mathrm{~mm}^{3}$ sections were fixed in 2.5\% phosphate buffered glutaraldehyde, post fixed in $2 \%$ osmium tetroxide, dehydrated in ethanol, cleared in propylene and embedded in epon resin. Ultrathin sections stained with uranyl acetate and lead citrate were examined with JEOL electron microscope.

Results: Cytotrophoblast, syncytiotrophoblast and giant trophoblastic cells of placentas of anaemic rats showed cytoplasmic and nuclear vacuolation with loss of cell margins. In addition, there was atrophy of microvilli on the cell surface, as well nuclear chromatolysis, nucleolar degeneration and appearance of dark bodies.

Conclusion: Chronic anaemia causes trophoblastic cell degeneration. This may undermine the functional integrity of the cells and constitute part of the mechanism for poor fetal outcome.
\end{abstract}

Keywords: anaemia; cytotrophoblast; degeneration; giant cells; placenta; syncytiotrophoblast

Anatomy 2017;11(2):72-78 @2017 Turkish Society of Anatomy and Clinical Anatomy (TSACA)

\section{Introduction}

Trophoblastic cells of the placenta comprise cytotrophoblasts, syncytiotrophoblast cells in the labyrinthine zone, and spongiotrophoblasts, trophoblastic giant cells in the junctional zone. ${ }^{[1-4]}$ The latter constitute the interhemal membrane or placental barrier. Anaemia causes adverse fetal outcome..$^{[5-8]}$ This poor outcome has been attributed to degenerative changes in the placenta which include reduction in size, placental infarcts, syncytial knots, decreased vascularity and fibrinoid necrosis. ${ }^{[2,9,10]}$ Trophoblastic cells are important in the function of the placenta and are sensitive to placental insult. ${ }^{[1-13]}$ Accordingly, knowledge of the effects of various insults is important in mitigating adverse fetal outcome. Studies on the anaemia induced ultrastructural changes in the placental trophoblastic cells are, how- ever, scarce, but nonetheless important in elucidating the basis for poor fetal outcome. This study therefore investigated the effects of anaemia on the ultrastructure of placental trophoblastic cells.

\section{Materials and Methods}

This experimental study was carried out on forty-nine female Sprague-Dawley rats. The animals were derived from a generation of clones over a 19 year period and divided into control and experimental groups. The study was approved by the ethical committee in the University of Nairobi and implemented in accordance with international policies and directives governing the use of animals in experiments. These directives were formulated to secure best environment and care for animals. Basic principles in 
Table 1

Effect of chronic anaemia on haemoglobin levels.

\begin{tabular}{lccc}
\hline & \multicolumn{3}{c}{ Hb (g/d): mean \pm SE } \\
\cline { 2 - 4 } Gestation day & Control & Chronic & p-value \\
\hline Day 17 & $12.88 \pm 0.23$ & $10.98 \pm 0.69$ & $.039^{*}$ \\
Day 19 & $12.98 \pm 0.16$ & $10.67 \pm 0.5$ & $.001^{*}$ \\
Day 21 & $13.4 \pm 0.5$ & $11.44 \pm 0.58$ & $.013^{*}$ \\
\hline${ }^{*} \mathrm{p}<0.05$ & & &
\end{tabular}

animal care were applied in this study which included the following: using less invasive techniques, optimum living conditions and medical care, causing no pain or distress, not performing unnecessary tests, reducing the number of animals tested to the minimum. Rats were handled with care, without rushing to avoid frightening the animals.

Chronic anaemia was induced by withdrawing $1.5 \mathrm{ml}$ of blood on five alternate days, through the retrobulbar plexus according to the protocol by Markovic et al. (2009). ${ }^{[14]}$ Anaemia was diagnosed when the haemoglobin level dropped below $12 \mathrm{~g} / \mathrm{dl}$. The mean haemoglobin level for the control rats was $13.1 \mathrm{~g} / \mathrm{dl}$; ranging from $12.88 \mathrm{~g} / \mathrm{dl}$ on day 17 to $13.4 \mathrm{~g} / \mathrm{dl}$ on day 21 . In anaemia on the other hand, haemoglobin was consistently below $12 \mathrm{~g} / \mathrm{dl}$ range from $10.98 \mathrm{~g} / \mathrm{dl}$ on day 17 to 11.44 on day 21 . The difference was statistically significant on all gestational dates. Chronic anaemic rats had mean values of haemoglobin concentration that are significantly less than those of the control mean values in all studied groups (Table 1).

Rats were anaesthetised by ether inhalation, the abdomen was opened using a midline incision, the uterus was exposed and placentas were extracted on days 17, 19 and 21 (Table 2). All placentas were cut in two equal parts. Half was processed for light microscopy and the other processed for transmission electron microscopy.

For light microscopy, the placentas were cut into 5 $\mathrm{mm}^{3}$ pieces, fixed in $10 \%$ buffered formaldehyde solution, dehydrated in alcohol, cleared in xylene and embedded in

Table 2

Distribution on rats on different gestational days.

\begin{tabular}{|c|c|c|}
\hline \multirow[b]{2}{*}{ Day } & \multicolumn{2}{|c|}{ Number of rats } \\
\hline & Control group & Experimental group \\
\hline 17 & 6 & 5 \\
\hline 19 & 5 & 8 \\
\hline 21 & 13 & 12 \\
\hline Total & 24 & 25 \\
\hline
\end{tabular}

paraffin wax. Five micron sections were cut, deparaffinized, stained with Hematoxylin and Eosin and examined at various magnifications in control and anaemic rats using a Leica ICC 50 microscope (Leica Microsystems, Wetzlar Germany). Photographs were taken using a high resolution digital camera attached to a computer.

For transmission electron microscopy, $1 \mathrm{~mm}^{3}$ tissue blocks of placenta were fixed in $2.5 \%$ phosphate buffered glutaraldehyde for two hours at $4^{\circ} \mathrm{C}$. They were then washed in $0.1 \mathrm{M}$ phosphate buffer $4 \times 20 \mathrm{~min}$ and then for 24 hours again at $4^{\circ} \mathrm{C}$. Secondary fixation was done in $2 \%$ osmium tetroxide in $0.1 \mathrm{M}$ phosphate buffer, $\mathrm{pH} 7.4$ for $1 \mathrm{hr}$ at room temperature. This was then followed by washing in double distilled water $4 \times 20 \mathrm{~min}$ at room temperature. Dehydration was done in ascending grades of ethanol, cleared in propylene oxide and embedded in epon resin. Semithin sections were cut at approximately 500-1000 nm thickness and stained with toluidine blue. Ultrathin sections were stained with uranyl acetate counter stained with lead citrate and then examined under JEOL transmission electron microscope at various magnifications using the protocols of Hunter ${ }^{[15]}$ and Bozzola and Russel. ${ }^{[1]]}$ Images were taken by high resolution camera.

\section{Results}

The trophoblastic cells in the placenta of control animals showed clear margins, cytoplasm, nuclei with distinct chromatin and nucleoli. Microvilli on the cytotrophoblasts were definite, long and numerous. Those in placenta of anemic animals, on the other hand, showed features of degeneration. The nucleus of the trophoblastic cells in the interhemal membrane showed features of chromatolysis such that the chromatin material appeared to have disappeared from the nucleus, leaving a naked nucleolus. The cell margins became indistinct. This was in contrast to the controls in which cells appeared distinct with clear margins, nucleus and prominent chromatin and nucleoli (Figures 1a and $\mathbf{b}$ ). The cells in the interhemal membrane displayed numerous dark bodies, vacuolation, disorganization, as well as degeneration of the endothelial lining with thickening of the basement membrane (BM) (Figures 1c and $\mathbf{d}$ ).

The syncytiotrophoblasts showed chromatin and nucleolar degeneration, cytoplasmic and nuclear vacuolation (Figures 2a and b). Cytotrophoblasts developed marked nuclear vacuolation and dark bodies. The surfaces facing the MBS bore microvilli which were reduced in number and the cells had different orientations on the surface of the cytotrophoblast (Figures $2 \mathbf{c}$ and $\mathbf{d}$ ). 

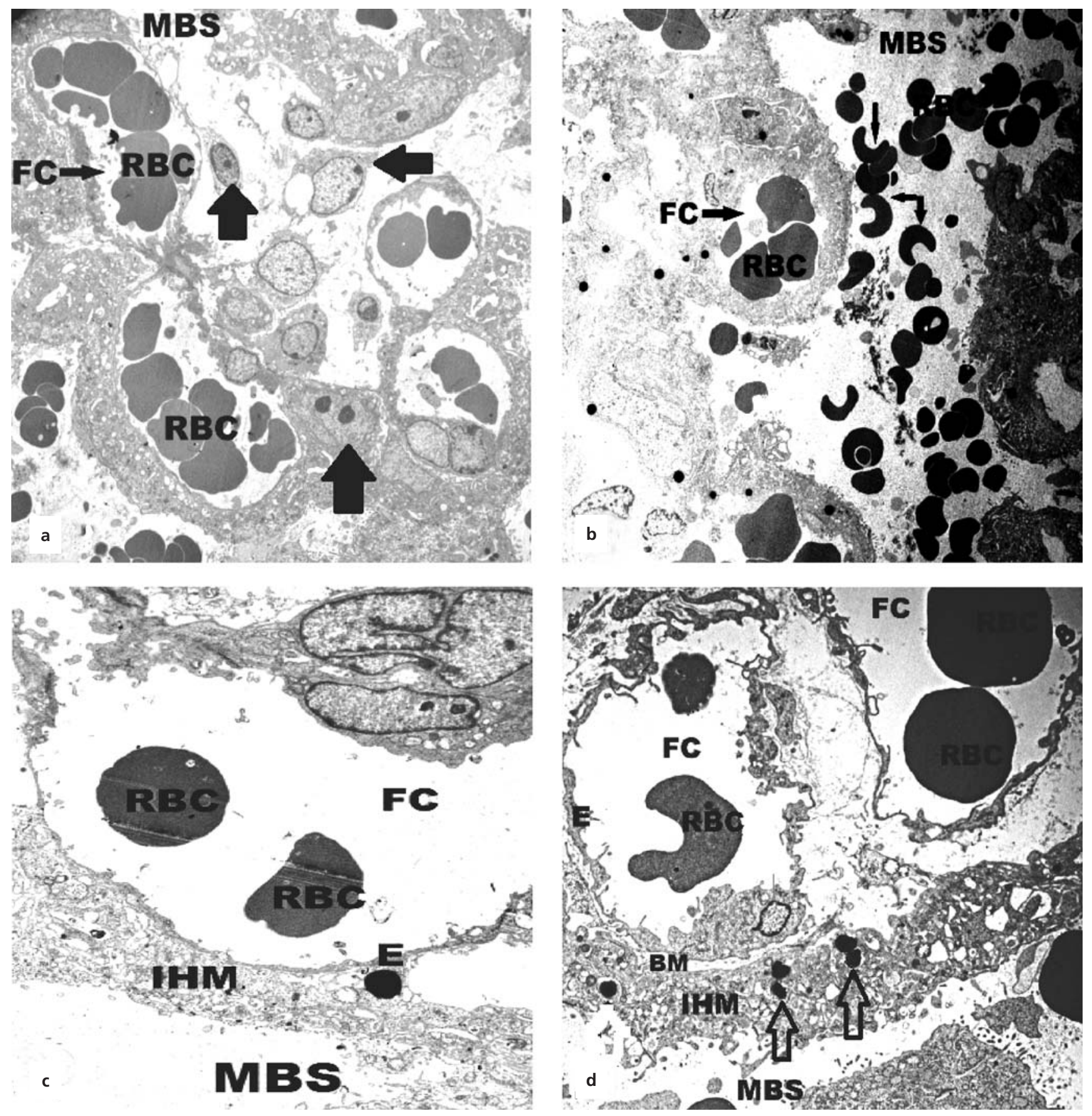

Figure 1. Electromicrographs of placental labyrinth in control and chronic anemic rat placenta at gestational day 21. (a) Electromicrograph of placental labyrinth in control rats showing normal maternal blood spaces (MBS), fetal capillaries (FC) with red blood cells (RBCs) and a number of giant cells with clear cell margins and prominent nucleoli (arrows) (x1200). (b) Electromicrograph of labyrinth in anaemic rats showing dilated MBS, fewer fetal capillary (FC), decreased numbers of giant cells and anisocytosis. Note the absence of clear cellular and nuclear margins of numerous dark bodies (x1200). (c) Electromicrograph of labyrinth of control animals showing FC with well-defined endothelial lining (E) and nuclei with 2 nucleoli. Note also the regular interhemal membrane $(\mathrm{IHM})(\times 3000)$. (d) Electromicrograph of labyrinth in anaemic rats showing abnormal shape and size of RBCs in FC, disorganization of E of FC and disruption of its wall, more dark bodies (arrows) and disorganized IHM ( $\times 3000)$.

Giant trophoblastic cells in control animals showed clear margins, granular cytoplasm, and prominent homogeneous nucleus with prominent nucleolus. In anaemia on the other hand, the giant trophoblastic cells lost cell margins, the cytoplasm and nucleus developed vacuoles, as the nucleolus disappeared (Figures $\mathbf{3}$ and $\mathbf{b}$ ). 

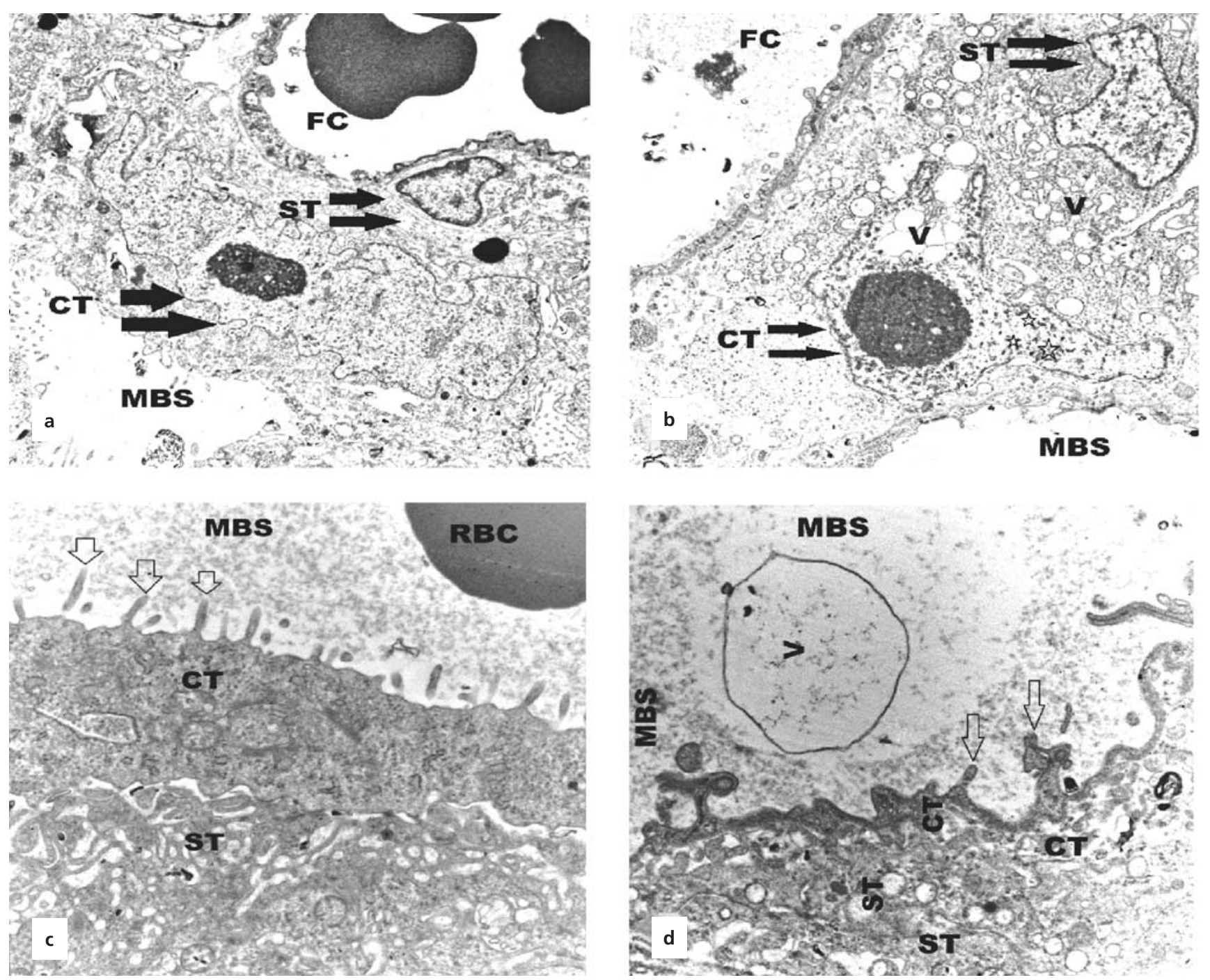

Figure 2. Electromicrographs of cytotrophoblasts and syncytiotrophoblasts of control and anemic rat placentae at gestational day 21. (a) Placenta of control rat with normal CT and ST lining the MBS and FC, respectively $(\times 5000)$. (b) Anaemic placenta showing vacuolation (V), chromatin and nucleolar disappearance in CT and ST (x5000). (c) Placenta of control, showing prominent long microvilli on CT (arrows) projecting into the MBS $(\times 10,000)$. (d) Anaemic placenta. Note the shorter and fewer microvilli (arrows) on CT cells $(\times 10,000)$. CT: cytotrophoblast; FC: fetal capillaries; MBS: maternal blood spaces; ST: syncytiotrophoblast.

The number giant trophoblastic cells in the anaemic group was relatively less compared to the controls (Figures $4 \mathbf{a}$ and $\mathbf{b}$ ).

\section{Discussion}

The cells most affected by anaemia were syncytiotrophoblasts, cytotrophoblasts and trophoblastic giant cells. Syncytiotrophoblasts and cytotrophoblasts showed changes characterized by nuclear and cytoplasmic vacuolation. Similar degenerative changes in these cells have been reported in hypoxia, ${ }^{[17,18]}$ pre-eclampsia ${ }^{[19]}$ and hypertensive disease of pregnancy. ${ }^{[20]}$ The changes are concordant with reports that these cells are sensitive to factors which cause placental injury ${ }^{[13,21,2]}$ Many of them, especially those related to hypoxia occur due to placental apoptosis consequent to oxidative stress. ${ }^{[23]}$ The syncytiotrophoblast is actively involved in the transport of metabolites to and from the embryo/fetus; production of hormones, growth factors and receptors which regulate maternal metabolism and placental development. ${ }^{[1,24]}$ Accordingly, the changes observed are likely to adversely impact on placental function by decreasing transfer and synthetic activity ${ }^{[18]}$ and hence contribute to poor fetal outcome. In addition, cytotrophoblastic cells 

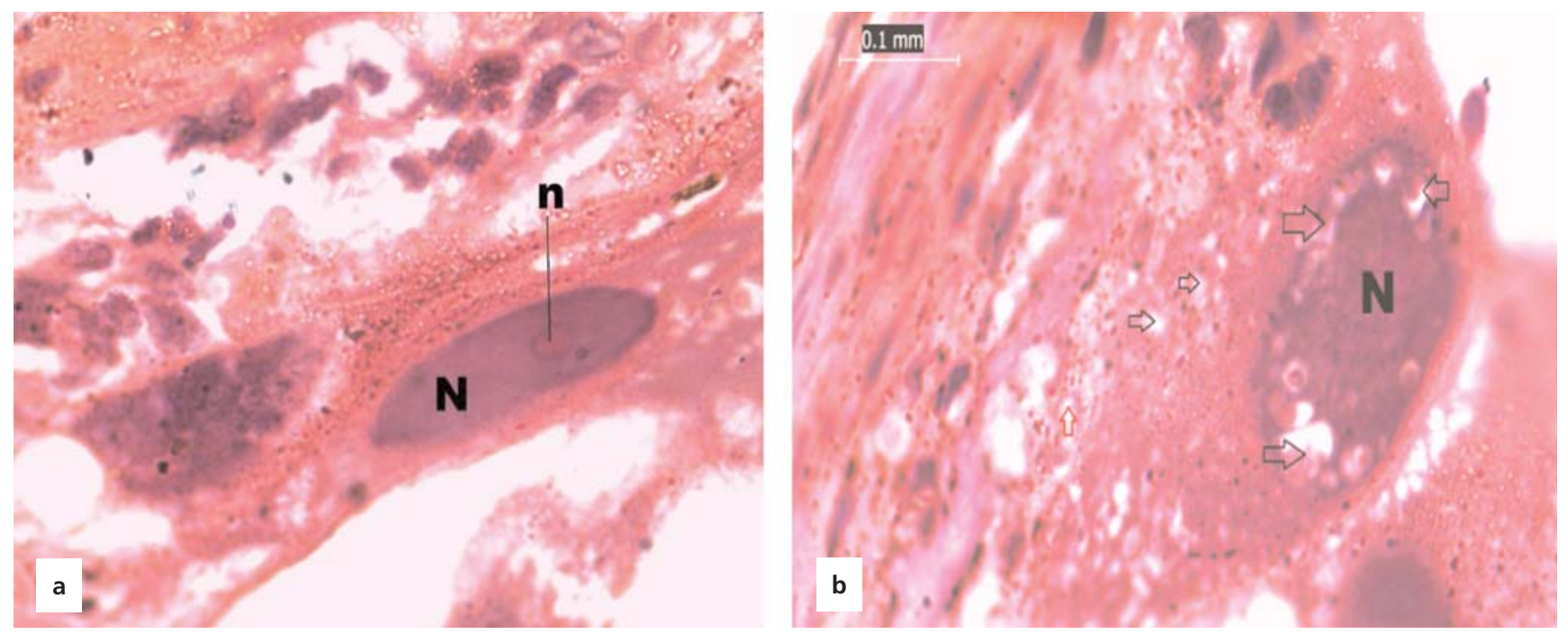

Figure 3. Photomicrographs of giant trophoblastic cells in rat placenta. (a) Giant cell in control at gestational day 17, showing normal homogeneous granular cytoplasm, uniform nucleus with prominent nucleolus. (b) Giant cell in anemia at gestational day 17 showing irregular cell margins, nuclear degeneration, cytoplasmic and nuclear vacuolation (arrows) (Hematoxylin and Eosin, $\times 1000)$. N: nucleus; n: nucleolus. [Color figure can be viewed in the online issue, which is available at www.anatomy.org.tr]

showed abnormal orientation, reduction in size and density of microvilli. The decreased microvillus density observed in the current study has also been reported in other complications such as IUGR placentae ${ }^{[25]}$ and preeclampsia. ${ }^{[17]}$ In the rat, cytotrophoblasts continuously differentiate into ST during villous formation and development and are important in invasion of blood vessels remodeling in early stages of implantation. ${ }^{[2]}$ Their degeneration may undermine placenta function, and contribute to poor outcome.

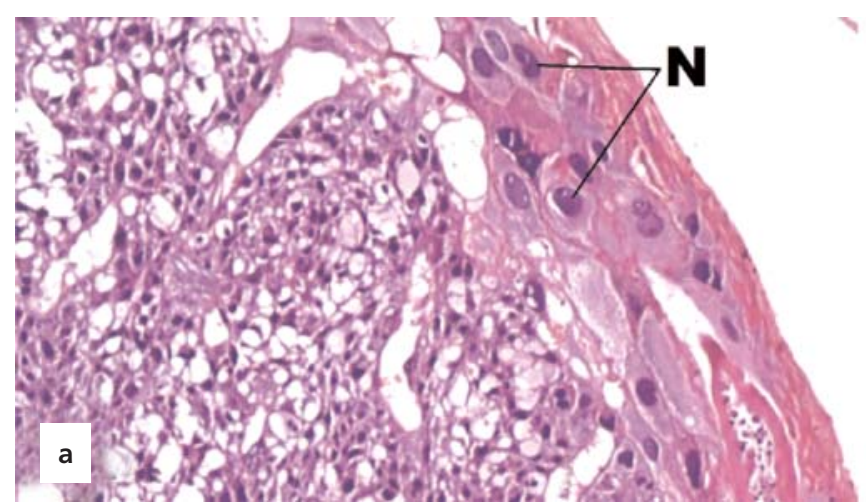

The trophoblastic giant cells secrete steroid hormones and prolactin related cytokines, to work on preparation and adaptation of the maternal body systems to pregnancy to ensure that proper placentation occurs. ${ }^{[12,27,28]}$ In the current study, these cells showed marked cytoplasmic and nuclear vacuolation. Similar degenerative changes have been reported in diabetes and hyperthermia, ${ }^{[2,30]}$ and placental chemical toxicity, ${ }^{[31-33]}$ and gestational protein restriction. ${ }^{[34]}$ They are probably genetically programmed. Indeed it has been reported

Figure 4. Photomicrograph of labyrinth and junctional zones in placenta of control rats at gestational day 19. (a) Giant trophoblastic cells in the control rat placenta showing normal distribution and appearance. Note the distinct dark nuclei (N) with definite nucleoli ( $\mathbf{n}$ ). (b) Giant cells in the anaemic group showing relative reduction in their number compared to the control. Note the nuclei ( $\mathbf{N}$ ) are lighter stained the nucleoli ( $\mathrm{n}$ ) are less distinct of giant cells. Hematoxylin and Eosin, $\times 100$. [Color figure can be viewed in the online issue, which is available at www.anatomy. org.tr] 
that $\mathrm{O}_{2}$ levels regulate cell fate through hypoxia induced factor-1 (HIF-1) which activates genes involved in cellular response to $\mathrm{O}_{2}$ deprivation. ${ }^{[32,35]}$ These morphological changes may alter placental function and embryo nutrition, and contribute to the poor fetal outcome.

\section{Conclusion}

Chronic anaemia causes trophoblastic cell degeneration. This may undermine the functional integrity of the cells and constitute part of the mechanism for poor fetal outcome.

\section{Acknowledgement}

We are grateful to technical staff in the Departments of Biochemistry and Human Anatomy for technical support, Prof Oduor-Okello for expert advice and Antonina Odock-Opiko for typing the manuscript.

\section{References}

1. Mayhew TM. A stereological perspective on placental morphology in normal and complicated pregnancies. J Anat 2009;215:77-90.

2. Soni R, Nair S. Study of histological changes in placenta of anaemic mothers. IOSR Journal of Dental and Medical Sciences 2013;9:42-6.

3. Cline JM, Dixon D, Ernerudh J, Faas MM, Göhner C, Häger JD, Markert UR, Pfarrer C, Svensson-Arvelund J, Buse E. The placenta in toxicology. Paper III: Pathological assessment of the placenta. Toxicol Pathol 2014;42:339-44.

4. Furukawa S, Kuroda Y, Sugiyama A. A comparison of the histological structure of the placenta in experimental animals. J Toxicol Pathol 2014;27:11-8.

5. Allen L. Anemia and iron deficiency: effects on pregnancy outcome. Am J Clin Nutr 2000;71:1280S-4S.

6. Noronha JA, Bhaduri A, Vinod H, Kamath A. Maternal risk factors and anaemia in pregnancy: a prospective retrospective cohort study. Obstet Gynaecol 2010;30:132-6.

7. Kiran N, Zubair A, Khalid H, Zafar A. Morphometrical analysis of intervillous space and villous membrane thickness in maternal anaemia. J Ayub Med Coll Abbottabad 2014;26:207-11.

8. Sabina S, Iftequar S, Zaheer Z, Khan M, Khan S. An overview of anemia in pregnancy. Journal of Innovations in Pharmaceuticals and Biological Sciences 2015;2:144-51.

9. Agarwal KN, Gupta V, Agarwal S. Effect of maternal iron status on placenta, fetus and newborn. International Journal of Medicine and Medical Sciences 2013;5:391-5.

10. Biswas S, Meyur R, Adhikari A, Bose K, Kundu P. Placental changes associated with maternal anaemia. Eur J Anat 2014;18:165-9.

11. Crocker IP, Tansinda DM, Jones CJ, Baker PN. The influence of oxygen and tumor necrosis factor- $\alpha$ on the cellular kinetics on term placental villous explants in culture. J Histochem Cytochem 2004;52:749-57.

12. Hu D, Cross JC. Development and function of trophoblast giant cells in the rodent placenta. Int J Dev Biol 2010;54:341-54.
13. Hung TH, Skepper JN, Charnock-Jones DS, Burton GJ. Hypoxiareoxygenation: a potent inducer of apoptotic changes in the human placenta and possible etiological factor in preeclampsia. Circ Res 2002;90:1274-81.

14. Markovic SD, Milosevic M, Dordevic N, Ognjanovic B, Stajn AS, Zorica S. Time course of hematological parameters in bleeding induced anemia. Archives of Biological Science Belgrade 2009;61: $165-70$.

15. Hunter E. Practical electron microscopy: a beginner's illustrated guide. 2nd ed. Cambridge (NY): Cambridge University Press; 1993.

16. Bozzola JJ, Russell LD. Electron microscopy. 2nd ed. Sudbury (MA): Jones and Bartlett Publishers; 1999.

17. de Luca Brunori I, Battini L, Brunori E, Lenzi P, Paparelli A, Simonelli M, Valentino V, Genazzani AR. Placental barrier breakage in pre- eclampsia: ultrastructural evidence. Eur J Obstet Gynecol Reprod Biol 2005;118:182-9.

18. Salgado SS, Salgado MKR. Structural changes in pre-eclamptic and eclamptic placentas - an ultrastructural study. J Coll Physicians Surg Pak 2011;21:482-6.

19. Selim ME, Elshmry NG, Rashed EA. Electron scanning microscopic observations on the syncitiotrophoblast microvillous membrane contribution to preeclampsia in early placental rats. J Blood Disord Transfus 2013;4:137.

20. Judson JP, Fun LP, Nadarajah VD, Nalliah S, Chakravathi S, Thanikhacalam P, Santhanaraj L. Ultrastructural and immunofluorescence studies of placental tissue in hypertensive diseases of pregnancy. Research Journal of Biological Sciences 2010;5:155-63.

21. Crocker IP, Barratt S, Kaur M, Baker PN. The in-vitro characterization of induced apoptosis in placental cytotrophoblasts and syncytiotrophoblasts. Placenta 2001;22:822-30.

22. Serin IS, Ozçelik B, Basbug M, Kiliç H, Okur D, Erez R. Predictive value of tumor necrosis factor alpha (TNF-alpha) in preeclampsia. Eur J Obstet Gynecol Reprod Biol 2002;100:143-5.

23. Grill S, Rusterholz C, Zanetti-Dällenbach R, Tercanli S, Holzgreve W, Hahn S, Lapaire O. Potential markers of preeclampsia-a review. Reprod Biol Endocrinol 2009;7:70.

24. Linton EA. Human trophoblast syncytialization: a cornerstone of placental function. Endocrine Abstracts 2005;10:515.

25. Battistelli M, Burattini S, Pomini F, Scavo M, Caruso A, Falcieri E. Ultrastuctural study on human placenta from intrauterine growth cases. Microsc Res Tech 2004;65:150-8.

26. James JL, Stone PR, Chainley LW. Cytotrophoblast differentiation in the first trimester of pregnancy: evidence for separate progenitors of extravillous trophoblasts and syncytiotrophoblast. Reproduction 2005;130:95-103.

27. Ain R, Canham LN, Soares MJ. Gestation stage-dependent intrauterine trophoblast cell invasion in the rat and mouse: novel endocrine phenotype and regulation. Dev Biol 2003;260:176-90.

28. Soares MJ, Konno T, Alam SM. The prolactin family: effectors of pregnancy-dependent adaptations. Trends Endocrinol Metab 2007; 18:114-21.

29. Padmanabhan R, Shafiullah M. Intrauterine growth retardation in experimental diabetes: possible role of the placenta. Arch Physiol Biochem 2001;109:260-71.

30. Padmanabhan R, Al-Menhali NM, Ahmed I, Kataya HH, Ayoub MA. Histological, histochemical and electron microscopic changes of the placenta induced by exposure to hyperthermia in the rat. Int J Hyperthermia 2005;21:29-44. 
31. Kosif R, Akta G, Öztekin A. Microscopic examination of placenta of rats prenatally exposed to aloe barbadensis: A preliminary study. Int J Morphol 2008;26:275-81.

32. Tait S, Tassinari R, Maranghi F, Mantovani A. Bisphenol A affects placental layers morphology and angiogenesis during early pregnancy phase in mice. J Appl Toxicol 2015;35:1278-91.

33. Omar AR, El-Din EYS, Abdelrahman HA. Implications arising from the use of cymbopogen proximus; proximal on placenta of pregnant albino rats. Brazilian Archives of Biology and Technology 2016;59: e16160165.

34. Rebelato HJ, Esquisatto MA, de Sousa Righi EF, Catisti R. Gestational protein restriction alters cell proliferation in rat placenta. J Mol Histol 2016;47:203-11.

35. Adelman DM, Gertsenstein M, Nagy A, Simon MC, Maltepe E. Placental cell fates are regulated in vivo by HIF-mediated hypoxia responses. Genes Dev 2000;14:3191-203.

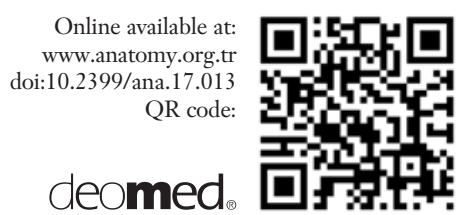

Correspondence to: Omer Awad, MSc

Department of Human Anatomy, University of Nairobi,

P.O. Box: 30197 Nairobi, Kenya

Phone: +254 731426117

e-mail: omarawad12@yahoo.com

Conflict of interest statement: No conflicts declared.

This is an open access article distributed under the terms of the Creative Commons Attribution-NonCommercial-NoDerivs 3.0 Unported (CC BY-NCND3.0) Licence (http://creativecommons.org/licenses/by-nc-nd/3.0/) which permits unrestricted noncommercial use, distribution, and reproduction in any medium, provided the original work is properly cited. Please cite this article as: Awad O, Ochieng SJ, Malek A, Ogeng'o J. Chronic anaemia causes degenerative changes in trophoblast cells of the rat placenta. Anatomy 2017;11(2):72-78. 